Utah State University

DigitalCommons@USU

9-26-2018

\title{
Troubleshooting Personnel's Satisfaction with Software Tools
}

Robert Heaton

Utah State University

Follow this and additional works at: https://digitalcommons.usu.edu/lib_pubs

Part of the Library and Information Science Commons

\section{Recommended Citation}

Robert Heaton (2018) Troubleshooting personnel's satisfaction with software tools, Journal of Electronic Resources Librarianship, 30:3, 119-130, DOI: 10.1080/1941126X.2018.1493977

This Article is brought to you for free and open access by the Libraries at DigitalCommons@USU. It has been accepted for inclusion in Library Faculty \& Staff Publications by an authorized administrator of DigitalCommons@USU. For more information, please contact digitalcommons@usu.edu.

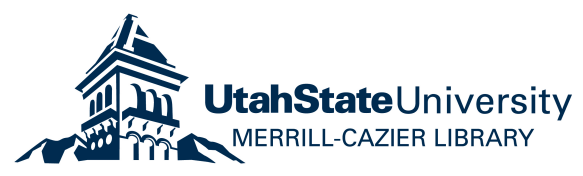




\begin{abstract}
An exploratory survey of midsize land-grant institutions in 2016 investigated factors that were potentially correlated with how satisfied library personnel were with the software tools they used in electronic-resource troubleshooting. Although the study was very small in scale, it found that troubleshooting personnel at responding libraries are generally satisfied with the tools they use, with no apparent correlation with the area of troubleshooting activity to which the tool is applied, whether the tool is also used by non-troubleshooting personnel at the institution, or whether the tool was evaluated prior to implementation. The data weakly suggested that satisfaction was positively correlated with whether troubleshooting personnel were involved in the decision to implement the tool and negatively correlated with the length of time the tool has been in use.
\end{abstract}

Keywords: troubleshooting, tools, software, user satisfaction, electronic resources, access

Author's note: Robert Heaton is Collection Management Librarian at the Merrill-Cazier Library, Utah State University, 3000 Old Main Hill, Logan UT 84322-3000. Email:

robert.heaton@usu.edu. ORCiD: 0000-0001-9067-1534.

Received: December 5, 2017

Accepted: March 23, 2018

This is the accepted manuscript following peer review. This article's version of record is available from Taylor \& Francis at https://doi.org/10.1080/1941126X.2018.1493977 


\section{Troubleshooting Personnel's Satisfaction with Software Tools \\ Introduction}

The field of librarianship is no stranger to studies of user satisfaction, especially in relation to technology. MacDonald (2015) identifies 2007 as a turning point in libraries' focus on patrons, with the appointment of the first User Experience Librarian and the creation of the Designing Better Libraries blog. Today library user experience is a thriving discipline, evidenced by such indicators as an Association for Research Libraries SPEC Kit (Fox \& Doshi, 2011), a dedicated journal (Welzenbach, 2014), and a LITA Guide on library service design (Marquez \& Downey, 2016). Libraries take cues from the business sector in attending to customer satisfaction and technology: corporations invested nearly $\$ 20$ billion in business-analytics software packages in 2016, an increase of over 9\% compared to the previous year (SAS Institute, n.d.). Within their

more-limited means, libraries go to great lengths to understand and then demonstrate the value of their collections and services for users. All libraries have the task of connecting these values to the needs that matter to their stakeholders, and in the case of academic libraries, this means meeting the priorities of institutional administrators. Therefore, such studies are easily justified.

These studies reliably filter into the literature of librarianship. EBSCO's Library, Information Science \& Technology Abstracts database includes the subject term "Library user satisfaction," which returns at least two dozen papers from each of the last several years. In contrast, as far as the author could determine, the index's thesaurus includes no comparable entry for the satisfaction of library personnel, and therefore none on their satisfaction with the tools they use to accomplish their work. This area of research has considerable room for growth in the literature (though an uptick in Librarian Satisfaction Librarians seems unlikely). 
In order to begin addressing this gap, the author surveyed library personnel responsible for electronic-resource troubleshooting at institutional peers. From the responses to that small-scale survey, this article addresses the following research questions:

Q1. How satisfied are library personnel with the tools they use for troubleshooting?

Q2. What factors influence the satisfaction of library personnel with the tools they use for troubleshooting?

\section{Literature Review}

A growing body of literature addresses various aspects of electronic-resource troubleshooting (e.g., Carter \& Traill, 2017; Rathmel, Mobley, Pennington, \& Chandler, 2015; Samples \& Healy, 2014). In contrast, as mentioned above, research on user satisfaction with the tools used in troubleshooting is sparse. The e-resources literature does, however, cover librarian satisfaction with software implementations in general and the actions they take during evaluation or implementation with the goal of making the process more likely to succeed.

Most mentions of satisfaction levels in the published literature on e-resource management are decidedly negative; nearly all refer to electronic resource management systems (ERMS). Although it was almost ten years ago, Doering \& Chilton (2008) cited "[m]ounting evidence that commercial ERMs were not living up to expectations," with the memorable anecdote of attending a library conference where in an informal survey of the room, half of the attendees used a vendor-produced ERMS, but "no one was happy with his or her system" (p. 46; emphasis in original). At the same time, after implementing Ex Libris's Verde ERMS at Kansas State University, Ekart (2008) gave this lukewarm praise: “We're still left with processes spread across departments and too much information [solely] in people's heads, but now there's a place, a centerpiece to build a sensible workflow around" (p. 45). Hartnett, Price, Smith, and Barrett 
(2010) chose to implement a replacement ERMS after their initial vendor discontinued support but not before learning on their own that "Many features did not work, others did not work well. Promised features were never realized, and [the ERMS] never did integrate successfully with our other systems" (p. 23). Collins and Grogg (2011) surveyed academic librarians and software vendors on their priorities for an ERMS and learned that one of respondents' highest priorities, "workflow or communications management," was also "one of the biggest deficiencies . . of ERMS functionality" (p. 23). In their study of the "Tools, Techniques, and Training" related to e-resources troubleshooting, Rathmel, Mobley, Pennington, and Chandler (2015) "did not ask about satisfaction with current tools, but survey comments and the literature indicate there is much room for improvement" (p. 98). Only this last article focused specifically on tools used in troubleshooting, and this was its only mention of satisfaction.

Through conscious planning, some libraries have avoided such negativity in their ERMS implementations. Gustafson-Sundell (2011) outlined the process and outcomes of exploring ERMS options at the Northwestern University Library. Gustafson-Sundell cautiously asserted that through a careful review of the literature, compilation of basic requirements, narrowing to a list of finalist products, and seeking workarounds other than an ERMS instance, the Library "has made satisfying progress toward better electronic resources management” (p. 139). Anderson (2014) described one library's extensive process of developing "a very clear list of what they were hoping to accomplish with [an ERMS] implementation," followed by "talking to the vendor ... [,] going to area user groups, speaking to the staff of other libraries . . ., and making sure that the systems evaluated could fulfill the highest priority needs" (p. 26). Anderson found that this led to a high level of satisfaction and claimed that librarians "that said they were less happy with 
[their ERMS] said they had decided on the product for other reasons, such as financial constraints or a desire to stay completely with one software vendor” (p. 26).

Along with conducting a formal evaluation, several specific factors emerge in the literature on choosing and implementing a new software tool that are intended to ensure later success with that tool. The chosen "systems need to be fully adopted and supported in the organization; otherwise, use will decline and the usefulness will diminish" (Rathmel et al., 2015, p. 97). Wilson (2011) indicated that in one case, "implementation was made easier simply by the fact that the librarians were able to piggyback on other library or campus units that were already using the systems in question," making such adoption and support more likely to be seamless (p. 302). Ennis and Tims (2012) chose a platform for building an issue-reporting tool because of its ability to automate a previously manual process (i.e., email forwarding based on predefined roles in a workflow; p. 8). Rathmel et al. (2015) also indicated that "systems used should be robust, flexible, and able to support library needs to ensure sustained use by library staff' (p. 97). References to factors similar to these were included in the survey whose results are reported in this article.

\section{Method}

This study was designed to learn about the tools used for library electronic-resource troubleshooting, including how satisfied troubleshooting personnel are with the performance of those tools. A survey was administered beginning April 15, 2016, to those institutions selected by its Board of Regents as peers of Utah State University, the author's home institution (see Table 1). This population of eleven midsize land-grant universities (including the author's own) was chosen not only because the findings would be immediately applicable to the author's institution but because those institutions' budgets, enrollment, and staff sizes vary considerably, 
making it easier for many different readers to identify with the findings. The survey received an overall response rate of between $4(36 \%)$ and $6(55 \%)$, but for the questions regarding satisfaction rates, only four responses were received. Given the small sample size of this study, its results cannot be reliably generalized even to the study population. Instead, the study is intended to generate preliminary data and start a discussion about how library personnel can better choose the software they use and ensure its successful implementation.

Table 1

Data Profile for Utah State University and Peer Institutions

\begin{tabular}{lrr}
\hline \multicolumn{1}{c}{ Institution } & $\begin{array}{c}\text { Student } \\
\text { Enrollment } \\
\text { (FTE) }\end{array}$ & $\begin{array}{c}\text { Library } \\
\text { Expenditures } \\
\text { (USD) }\end{array}$ \\
\hline Colorado State University & 25,903 & - \\
Washington State University & 24,712 & $14,136,589$ \\
Oregon State University & 22,544 & $9,627,311$ \\
University of Nebraska-Lincoln & 22,342 & $16,213,094$ \\
Kansas State University & 21,235 & $14,676,605$ \\
Utah State University & 20,017 & $8,820,015$ \\
University of Nevada-Reno & 15,145 & $9,690,193$ \\
New Mexico State University & 14,984 & $7,180,791$ \\
Montana State University & 11,779 & $7,922,366$ \\
University of Wyoming & 11,100 & $12,632,877$ \\
University of Idaho & 10,968 & $7,291,039$ \\
\hline Comparison group median & 18,190 & $11,161,535$ \\
\hline
\end{tabular}

Note. FTE = full-time equivalent. No expenditure data were reported by Colorado State University. Data from "Compare academic libraries," by the National Center for Educational Statistics (2013), https://nces.ed.gov/surveys/libraries/Compare/Default.aspx.

In order to identify possible factors contributing to personnel's satisfaction with those tools, the survey included several sections, each related to a different area of the practice of e-resource troubleshooting. These sections included: personnel with troubleshooting responsibilities, the tools used in a range of software categories, the duration each tool has been in use, the troubleshooting activities in which each tool is used, the respondents' satisfaction with each tool 
for each of those activities, some details about each tool's selection and implementation, and, finally, basic demographic information on the respondents. The survey results not directly related to library personnel's satisfaction with the tools they use were reported in a separate article (Heaton, 2018). These include the particular tools used, the areas of troubleshooting activity for which the tools are used, and an analysis of tool use in relation to how troubleshooting is staffed.

The survey gathered information on the specific tools used for troubleshooting, but to generalize the responses into consistent groupings, the survey presented respondents with fourteen categories of software tools that might be used for troubleshooting, along with examples of each. These included such categories as ERMS, subscription-manager administration pages, and email. Respondents selected the tool categories that they used and then entered the specific tool names in free-text boxes. By presenting options in this way, the author hoped to prompt respondents to think of every tool that was possibly relevant to the study but without forcing them to adopt a conceptual model that did not correspond with their workflows. For example, respondents were free to list their customer-relations-management tool as an email program as well as a survey platform, depending on which features of the program they used. Tool categories were also presented separately from areas of troubleshooting activity. Even though certain tools lend themselves to certain activities, not all respondents may share the same ways of thinking about those tools and activities, and those unique uses of tools were of particular interest to the author.

The survey presented respondents with three overarching areas of troubleshooting activities to which each tool might be applied. These areas were articulated as follows: "Gather information to understand and replicate the issue," "Communicate issue status to users," and "Coordinate tasks among troubleshooting team and other library staff." To help reduce the length and 
complexity of the survey, the survey presented respondents with both the name and category of each tool selected earlier in the survey, and tool categories that were not selected earlier were not presented again. As an example, if a user typed "Sierra ERM" as her ERMS, "Outlook" as her email program, and "LibChat" as her chat program, the question would appear as shown in Figure 1.

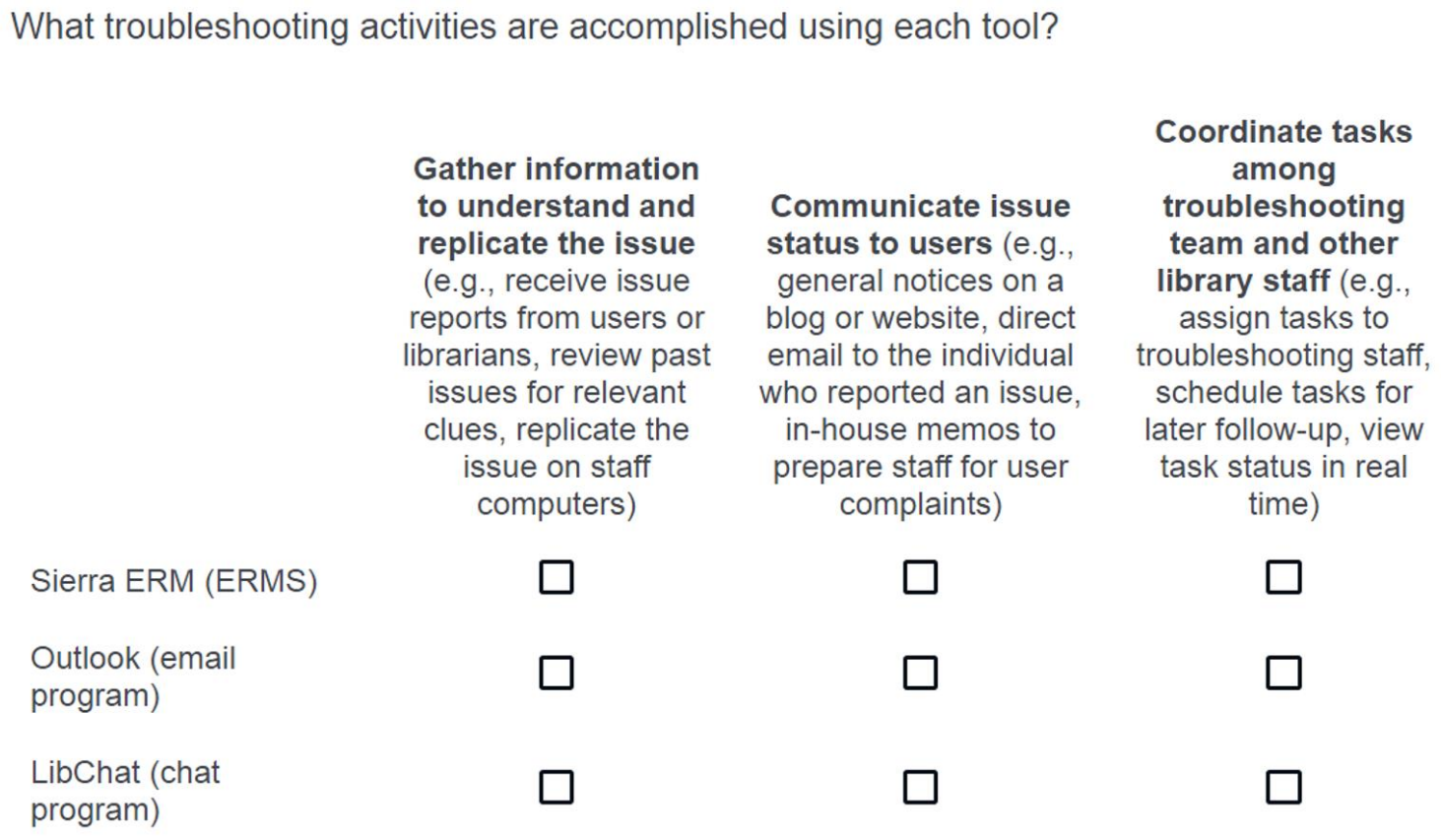

Gather information to understand and replicate the issue (e.g., receive issue reports from users or librarians, review past issues for relevant clues, replicate the issue on staff computers)

Communicate issue status to users (e.g., general notices on a blog or website, direct email to the individual who reported an issue, in-house memos to prepare staff for user complaints)

Coordinate tasks among troubleshooting team and other library staff (e.g., assign tasks to troubleshooting staff, schedule tasks for later follow-up, view task status in real time)

Sierra ERM (ERMS)

Outlook (email

program)

LibChat (chat

program)

Figure 1: Presentation of activities question for each tool category in survey instrument.

The survey questions related to the respondents' satisfaction with each tool were similarly formulated in relation to the activity areas that they selected earlier in the survey. Specifically, the questions were framed as follows:

- "How satisfied are troubleshooting staff with each tool's performance in the following activity: Gather information to understand and replicate the issue (e.g., receive issue reports from users or librarians, review past issues for relevant clues, replicate the issue on staff computers)?” 
- "How satisfied are troubleshooting staff with each tool's performance in the following activity: Communicate issue status to users (e.g., general notices on a blog or website, direct email to the individual who reported an issue, in-house memos to prepare staff for user complaints)?"

- 'How satisfied are troubleshooting staff with each tool's performance in the following activity: Coordinate tasks among troubleshooting team and other library staff (e.g., assign tasks to troubleshooting staff, schedule tasks for later follow-up, view task status in real time)?"

As with tool categories, these areas of activity were predefined in the survey with the intention of capturing information about troubleshooting activities that was unique but that could also be compared across institutions. For each tool that was chosen as one that the respondent applied to an activity, a five-point Likert scale was given, from extremely or somewhat satisfied to somewhat or extremely dissatisfied, with "neither satisfied nor dissatisfied" as a neutral option. In order to identify correlations with potential independent variables, the satisfaction data were analyzed in the aggregate as a composite index of satisfaction in all areas of troubleshooting activity. By including multiple data points for each respondent's tool list, this aggregation mitigates somewhat the low response rate for the survey's satisfaction questions.

The statements about the implementation process were given as follows:

- "Troubleshooting staff (and not someone else) selected the tool for use in troubleshooting"

- "The tool is used for non-troubleshooting purposes by other staff at the library or university" 
- "Staff applied a relatively formal evaluation or comparison process before adopting the tool"

- "Troubleshooting staff are relatively active in seeking a replacement for this tool" For each tool, respondents were instructed to select all that apply. As with other questions, only those tools categories selected as in use at a library were displayed in this question, along with the free text entered as the specific tool used.

\section{Results}

The following analysis considers respondents' satisfaction with troubleshooting tools used and seeks correlations between satisfaction and other factors. The first factor is the area of troubleshooting activity for which each tool is used, shown as Figure 2. As described in the method section, respondents gave a satisfaction rating on a 5-point Likert scale in response to the question "How satisfied are troubleshooting staff with each tool's performance in the following activity," where a description of one of three activity areas was displayed at a time along with the tools previously selected as used for that activity.

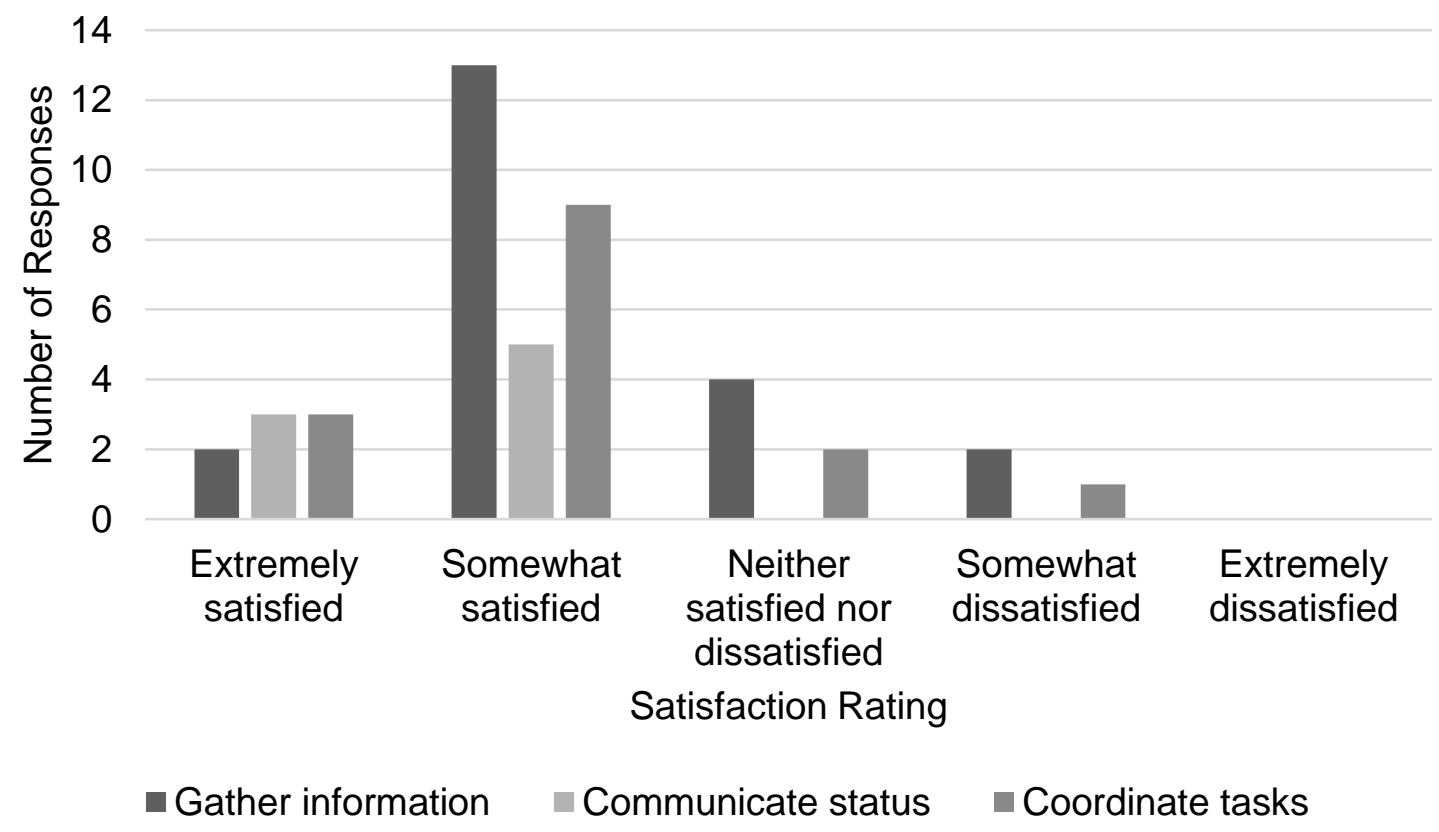


Figure 2: Satisfaction with all tools by activity area. $n=4$. Activity areas were predefined in the survey. Each respondent was counted once per rating per tool.

Satisfaction scores across the three activity areas were very similar. The sum of "Extremely satisfied" and "Somewhat satisfied" responses as a proportion of all responses for each area ranges from approximately $71 \%$ (15 of 21 responses) for gathering information to $100 \%$ (8 of 8 responses) for communicating the status of the issue patrons, with coordinating troubleshooting tasks in the middle at $80 \%$ (12 of 15 responses) for that activity. In general, troubleshooting personnel express satisfaction with the tools they use for all three activity areas. It is worth noting, however, that "Somewhat satisfied" responses outnumber "Extremely satisfied" responses by a factor of over 6 (13 vs. 2) for gathering information, of about 1.7 (5 vs. 3) for communicating issue status, and of 3 (9 vs. 3) for coordinating tasks. Feelings are positive but not overwhelmingly so.

Two respondents (50\%) expressed dissatisfaction with one or more tools used in some activity area. Among all satisfaction ratings, just under 7\% (3 of 44) indicated that respondents were "Somewhat dissatisfied," and no respondent reported being "Extremely dissatisfied" with a tool she uses for troubleshooting. In particular, one respondent was somewhat dissatisfied with an ERMS's support for gathering information about reported issues and with an email program's support for coordinating troubleshooting tasks among library personnel, and one other respondent was somewhat dissatisfied with an email program's support for gathering information about reported issues. In each of these cases, the frustration may stem from specialized requirements that go beyond the intended uses of the somewhat general tool of ERMS or the very general tool of email programs. 
No dissatisfaction was recorded in respondents' ability to communicate the status of reported issues to users. This was the area of activity with the fewest tools used. Only $18 \%$ (8 of 44 ) of satisfaction scores pertained to communicating issue status to users, which is just over half the $33 \%$ that would represent an even split of responses among the three activity areas. These libraries have found tools that are effective for meeting their needs even though a diverse range of tool categories are brought to bear on those needs, i.e., email, chat, ticket tracking, intranet, blog, and screenshot software. The needs of this activity area may simply be more straightforward than other areas' needs, or personnel may be satisfied with tools because they have been incorporated into clear workflows for communicating with library users.

The next figure does not include satisfaction scores but provides context for the figure that follows it. The survey asked, "For how many years has each selected tool been in use for troubleshooting purposes at your library?" The responses "under 1 year," "1-2 years," and “3 or more years" were provided, and the number of tools used for each length of time is shown in Figure 3.

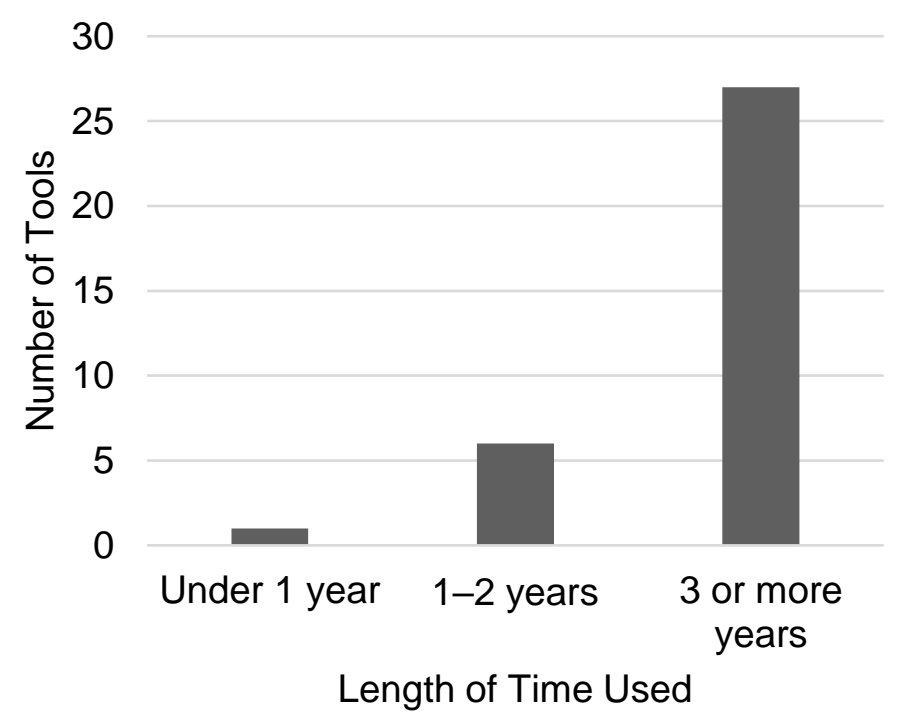

Figure 3: Number of tools by length of time used. $n=5$. 
One impetus for this project was the rapid development of online tools for business use, which might lead one to suspect that libraries have adopted or experimented with some of these. With this in mind, the survey presented users with the time bands on a relatively small scale. The responses, however, indicate that a longer view in the survey options may have been prudent. The most interesting finding related to the time software was in use was that only one library reported using only one tool for under one year (a customer-relations-management or tickettracking tool). This represented about 3\% (1 of 34) of all tools while all others had been used for at least one year. Even the "1-2 years" band was sparsely populated, with its 6 responses comprising around $18 \%$ (6 of 34) of tools. This left a surprising 79\% (27 of 34) of tools listed in the survey that had been in use for at least 3 years by the responding institutions' troubleshooting personnel. At least in their internal troubleshooting workflows, this sample has not rapidly embraced emerging technologies.

Although it lacks a nuanced range of times tools have been in use, Figure 4 plots satisfaction in terms of the tools' longevity. The two smaller time ranges were combined here into an "Under 3 years" band to simplify the chart without losing crucial context. As mentioned in the method section, the totals shown in each satisfaction level were calculated as the aggregate of all satisfaction ratings for a particular tool in every activity area in which it is used. 


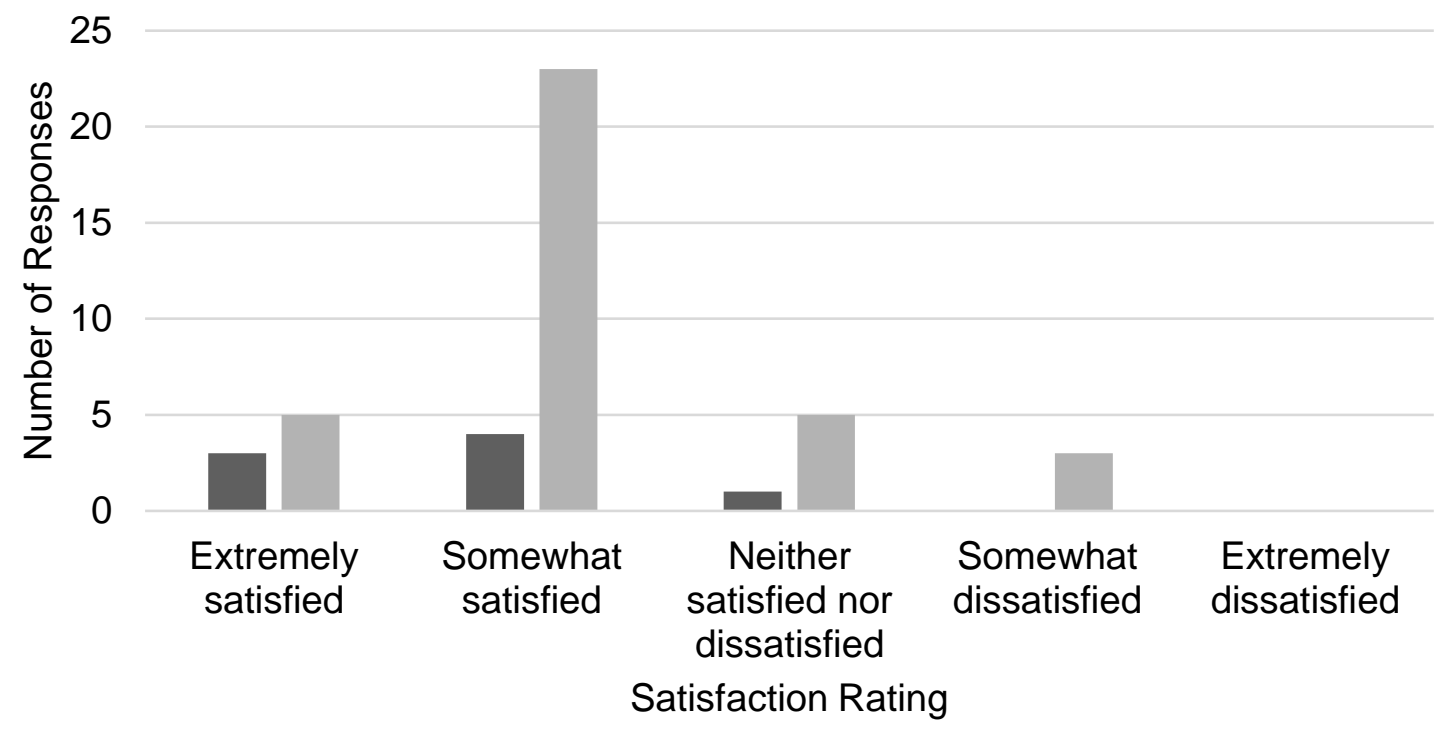

- Under 3 years $\quad 3$ or more years

Figure 4: Satisfaction with all tools by length of time used. $n=4$. Responses of "Under 1 year" and "1-2 years" were combined into the "Under 3 years" grouping.

As already mentioned, the responses skew sharply toward satisfaction, and this trend is comparable between longstanding troubleshooting tools and those adopted more recently. The sum of "Extremely satisfied" and "Somewhat satisfied" scores makes up 78\% (28 of 36) of all responses for those tools used for three or more years and 88\% (7 of 8) of responses for tools used for under three years. Again, the few "Somewhat dissatisfied" scores come from an ERMS and an email program at two different institutions, and because these are general tools, as mentioned before, this may be linked to factors unrelated to troubleshooting. No respondent reported dissatisfaction with a recently adopted tool, but more-granular reporting of duration data may clarify whether this is an authentic trend.

Figure 5 uses the same aggregation method as described above but as measured against respondents' stated involvement in selecting each tool to be implemented. The option was worded as "Troubleshooting staff (and not someone else) selected the tool for use in 
troubleshooting"; selecting that choice contributed to the count of responses "Involved" in the selection process while leaving it deselected counted as "Not involved."

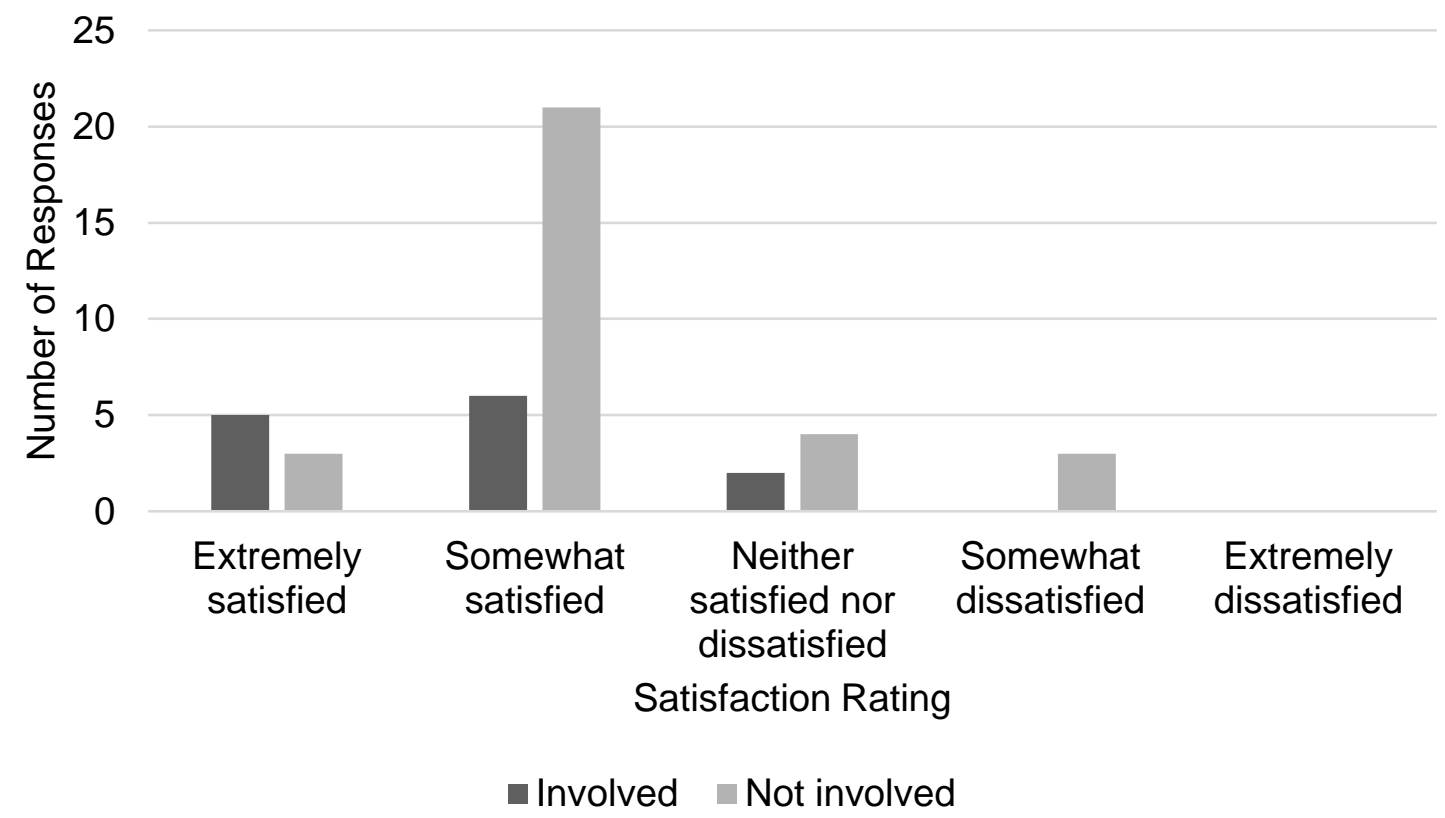

Figure 5: Satisfaction with all tools by whether troubleshooting personnel were involved in the implementation decision. $n=4$.

It is difficult to discern a possible correlation between troubleshooting personnel's involvement in selecting a tool and their satisfaction with it. One reason for this is that the majority of tools $(84 \%$, or 37 of 44$)$ were implemented without the involvement of troubleshooting personnel. It is possible that some libraries (or their parent institutions) mandated the use of particular software and did not solicit input from those using it. However, a more likely scenario may be that the software was chosen before those individuals worked there, so they were not personally involved in the decision even though personnel in place may have been consulted at the time. The data's negative responses do suggest support for the hypothesis. The three negative ratings (all "Somewhat dissatisfied") were given by personnel who did not have the benefit of involvement in selecting that tool. A larger data set may bear out this 
observation or challenge it, but the lack of any "Involved" and "Dissatisfied" pairing is suggestive.

With the possible exceptions of ERMS, subscription managers, and (arguably) ticket trackers and screenshot tools, most tools are used by library personnel other than those involved in troubleshooting. This leads to the next yes-no option raised in the survey: "The tool is used for non-troubleshooting purposes by other staff at the library or university." Again, this is likely the case for such common tools as email, calendar, and spreadsheet software as well as some libraries' implementations of an intranet or tools for blogging, project management, or file sharing. Because of the availability of formal and informal support networks for such broadly used tools, it was anticipated that satisfaction scores would be higher in those cases. Figure 6 represents the satisfaction-index scores for all tools across all activities on the basis of whether they are used by others at the institution.

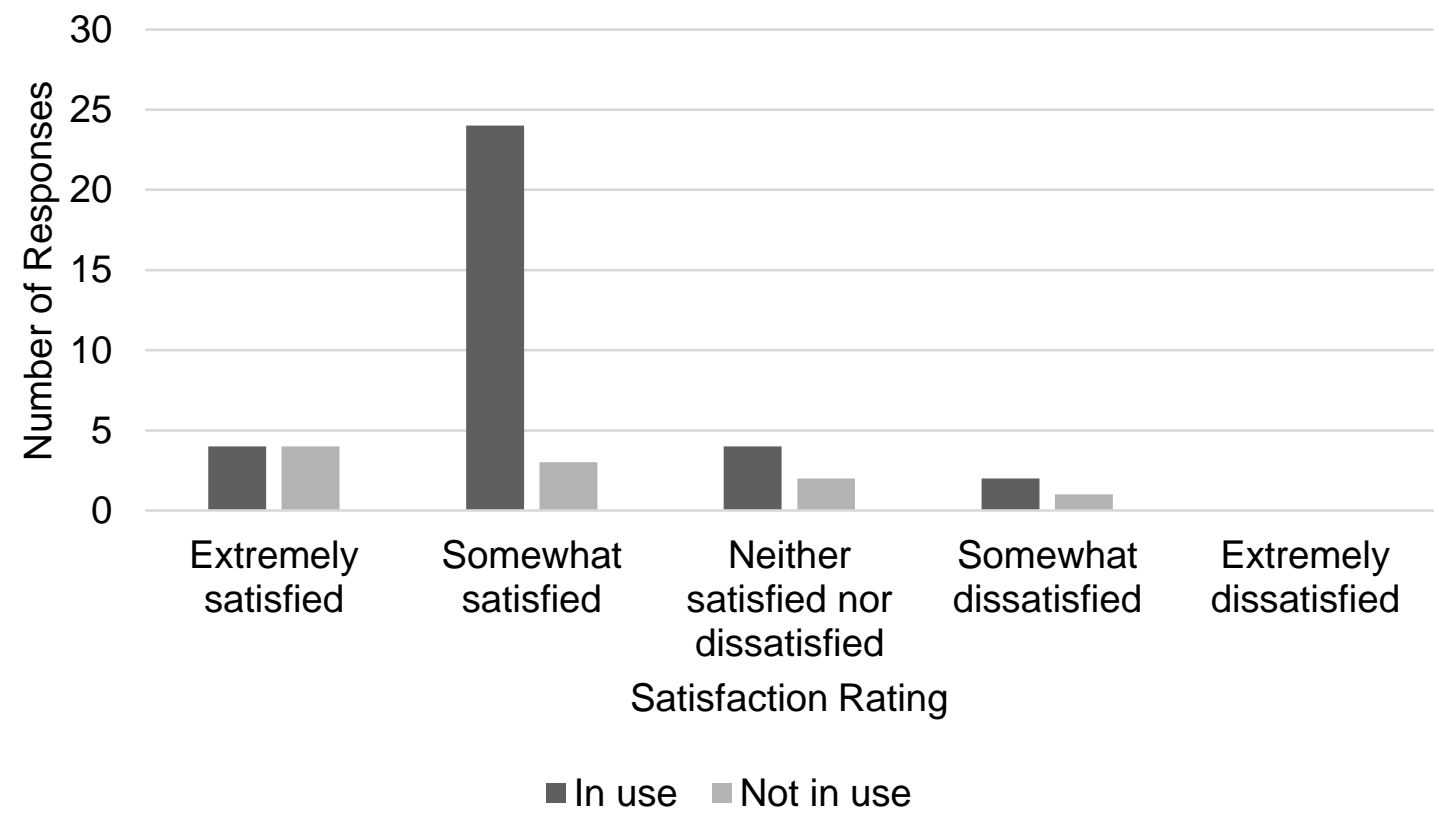

Figure 6: Satisfaction with all tools by whether the tool is used by non-troubleshooting personnel at the institution. $n=4$. 
The vast majority of tools $(77 \%$, or 34 of 44$)$ were in fact used more widely than solely for troubleshooting. Because so much work today revolves around such ubiquitous tools as Microsoft Outlook, this is perhaps unsurprising. Those tools' ubiquity also may lead users to take for granted that they function properly. They are no longer something about which one bothers to form an opinion: they simply exist, and everyone is resigned to using them. A similar principle may come into play even with less common tools. When a user accepts the paradigm in which, say, a ticket tracker operates, she will naturally perceive it as succeeding in its intended tasks. The lack of diversity and creativity in the list of tools used at the respondents' institutions (as based on the responses to this question) suggests that such status-quo thinking may be a compelling factor in many libraries' e-resource operations. As with other questions, there were so few negative satisfaction scores, both for tools used only for troubleshooting and those used outside of it, that no general conclusions are suggested.

The final two measures of satisfaction are unique and perhaps surprising because very few respondents either participated in a formal evaluation of any tools prior to their implementation or are actively seeking a replacement for any tools. Figure 7 shows satisfaction scores in relation to the question, "Staff applied a relatively formal evaluation or comparison process before adopting the tool." The few instances where a more or less formal evaluation of a tool took place predictably align with the general trends: troubleshooting personnel tend to be happy with their tools. It is interesting, however, that of only five ratings of tools evaluated before implementation, there was one "Somewhat dissatisfied" response. This directly contradicts the hypothesis that troubleshooting personnel will be more satisfied with the performance of a tool that was evaluated prior to implementation than with one that was not. The likely staff turnover mentioned in relation to Figure 5 may help explain the outlier here as well. It does not matter if 
the tool was evaluated at the time of its implementation if the people evaluating it then were different from the people using it now. Analyzing the satisfaction scores against other possible independent variables may, by comparison, weaken the apparent correlation between an evaluation process and later dissatisfaction.

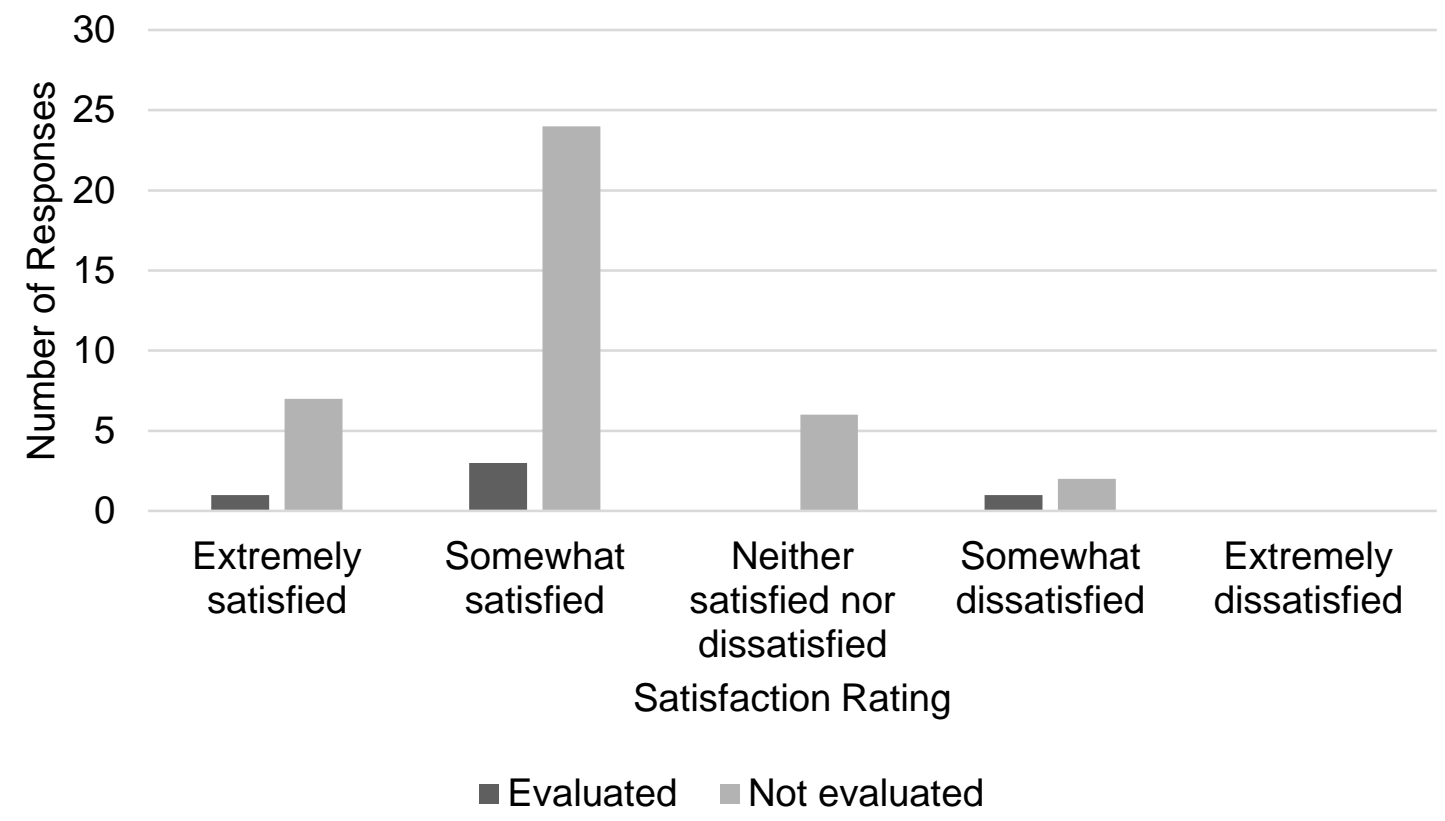

Figure 7: Satisfaction with all tools by whether the tool was evaluated prior to implementation $n=4$.

As also mentioned previously, many tools are used more widely than just for e-resource troubleshooting. This again removes the conditions undergirding the hypothesis: even though a tool was thoroughly vetted before being put into place, its suitability for the activities of troubleshooting was not necessarily considered during that process.

The final factor against which satisfaction ratings were tested was the active seeking of a replacement for the tool in question, as shown in Figure 8. Unfortunately, this set of data is even sparser than the one plotted above, with satisfaction scores corresponding to only a single respondent seeking to replace a single tool—an ERMS. The chart, with only one affirmative response on the basis of the independent variable, says very little about tools for which a 
replacement is being sought, but the bulk of the data here supports the hypothesis. The evidence shows that those respondents not actively seeking to replace a particular tool are on the whole satisfied with the tool's performance. In that light, the contrasting points are in fact the two "Somewhat dissatisfied" ratings upon which no action is being taken. If they are dissatisfied, why are they doing nothing about it? The same institutional characteristics suspected to influence the study's other questions might reasonably be alleged here: a librarian is too new to have enough experience with the tool to seek a replacement for it; no formal process is in place for initiating the review of alternatives; or most tools are used by many other people, which makes the process slower and less likely to happen on the basis of one group or individual's opinion.

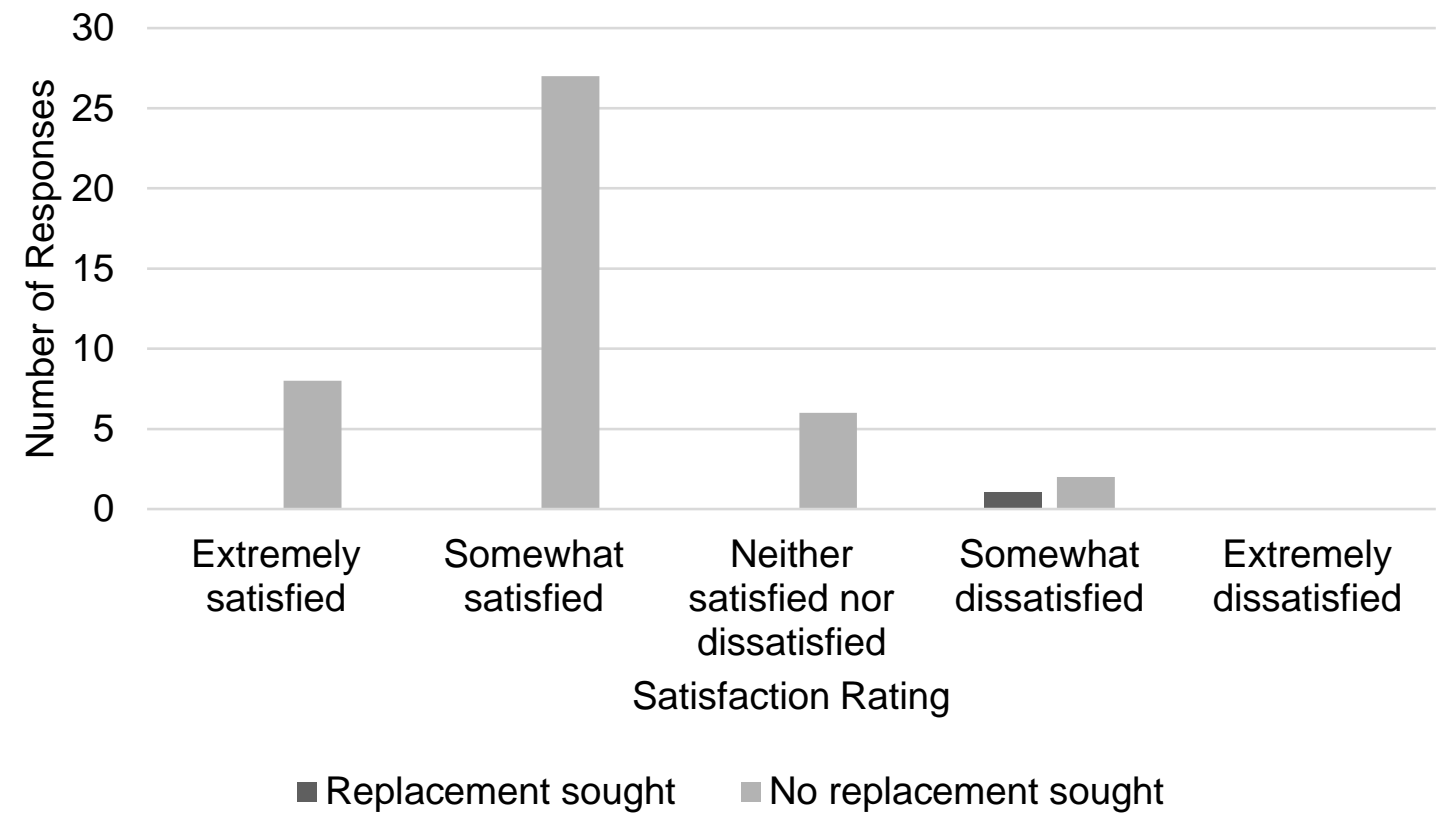

Figure 8: Satisfaction with all tools by whether a replacement for the tool is actively being sought. $n=4$.

\section{Discussion}

This section returns to the two research questions stated in the introduction and presents a brief discussion based on the findings.

Q1. How satisfied are troubleshooting personnel with the tools used? 
The professional associations of librarianship tout technological literacy as an important value. As the accrediting body for library schools in North America, the American Library Association issued a Core Competencies of Librarianship document in 2009 (American Library Association, 2009). Among many other things, the Core Competencies asserts that graduating students "should know and, where appropriate, be able to employ ... [t] he methods of assessing and evaluating the specifications, efficacy, and cost efficiency of technology-based products and services" (2009, p. 1, 3). The NASIG Core Competencies for Electronic Resources Librarians reaffirms this requirement for librarians who manage e-resources (NASIG Core Competencies Task Force, 2016, pp. 4-5). Of course these "technology-based products and services" include those that libraries make available to users, but should it not also include the tools used behind the scenes to deliver services effectively? NASIG codifies just such a notion in stipulating that an e-resources librarian "[e]valuates existing procedures and workflows, revising or replacing them as needed to maximize efficiency and job performance" (2016, p. 8). Unfortunately, the library literature provides very little support for doing so. The activities related to troubleshooting are only one example of this gap.

To begin building a literature for evaluating and implementing software tools in troubleshooting, some baseline knowledge is needed: What tools are currently in use, and do those using them consider them effective? The urgency of further research rests on the question of user satisfaction.

As shown in Figure 2, the sample of troubleshooting personnel in the present study find that the software tools they currently use do meet their needs. For all tools used across all troubleshooting activities, $93 \%$ of satisfaction scores were neutral or positive. Setting aside the "neither satisfied nor dissatisfied" ratings and focusing on the activity area with the lowest 
satisfaction scores, the results remain strongly positive: as described above, respondents found that their tools for gathering information about an access issue were at least somewhat satisfactory in $71 \%$ of cases. Although the literature does not address personnel satisfaction with the tools used in troubleshooting, this finding contradicts the generalization that "there is much room for improvement" (Rathmel, Mobley, Pennington, \& Chandler, 2015, p. 98) as cited in this article's literature review. Those who are frustrated with current software may continue to be frustrated because this finding gives vendors little incentive to improve their offerings. On the other hand, future researchers desiring to challenge the status quo can address whatever failings may exist by confronting user dissatisfaction more directly whereas it was incidental to this study.

Q2. What factors influence the satisfaction of troubleshooting personnel with the tools used?

Several factors were drawn from good practices for software adoption in the library literature in order to compare their relative influence on user satisfaction. E-resource managers want to know what tools will best support their tasks and workflows, and it was hoped that the study would isolate the factors most and least likely to lead to successful software adoption.

These factors were explored for possible correlations with satisfaction rating:

- Area of troubleshooting activity for which the tool is used

- Length of time the tool has been in use

- Whether troubleshooting staff were involved in the decision to implement the tool

- Whether the tool is used by non-troubleshooting personnel at the institution

- Whether the tool was evaluated prior to implementation

- Whether a replacement for the tool is actively being sought 
These each imply a hypothesized recommendation (e.g., some areas of troubleshooting activity lend themselves to greater ease and therefore satisfaction with tools; using a tool longer leads to greater familiarity and therefore satisfaction). However, the conclusions drawn from the data are much more tentative. There were some indications that the activities related to communicating the status of an issue to users was slightly better supported by software tools than were the activities of gathering information about the issue or coordinating the tasks associated with resolving it. Satisfaction could be not be reliably connected to years a tool had been in use, but none of the dissatisfied respondents were recent adopters. Many respondents were quite satisfied with tools they had no part in selecting, but all of the dissatisfied ratings came from those personnel who were not involved; being part of the selection process may make failure less likely but does not guarantee success. Respondents were generally happy with the tools that nontroubleshooting staff are also using. A concrete process for evaluating a tool prior to implementation generally but inconsistently led to a better satisfaction score. And finally, although both numbers are small, among those dissatisfied with a tool, those maintaining the status quo outnumber those actively seeking to replace it.

Future researchers may benefit more from a discussion of confounding influences than of the findings themselves. These are similar to factors identified by Anderson, such as "financial constraints or a desire to stay completely with one software vendor" (2014, p. 26), that are independent of the software's usability or fitness for a given purpose. The first foundational influence was that respondents overwhelmingly (79\%) reported having used their troubleshooting tools for at least three years. Because of the speed at which new software tools become available (at least in the non-library market), the lack of more-recent adoptions was unexpected. This may not necessarily imply that users are satisfied with their tools: when the 
process of evaluating and implementing a tool is particularly lengthy, it logically prevents a change from happening more quickly. For example, integrated library systems were included in the survey insofar as ERMS modules were integrated into those systems, and their longevity indicated in the survey responses may mean nothing more than that insufficient time has passed since the implementation of the current tool to make a move to the next one feasible.

An outgrowth of this first influence is the possibility of employee turnover in the years following the selection and implementation of most tools that troubleshooting personnel use. This reality may (or may not) explain why the majority (84\%) of tools were implemented without the involvement of troubleshooting staff. (Accepting this as a confounding influence assumes that, in at least some cases, respondents either did not know whether earlier staff had been included in the process or simply knew that they themselves had not.) Similarly, even the most carefully planned and executed process for evaluating new products cannot guarantee that current personnel will have success in using a software tool—and predicting changes to workflows and the aptitudes and tastes of future staff is practically impossible. In short, long implementation timelines and high staff turnover may interfere significantly with the effective selection of tools used in troubleshooting. The author was unable to find any literature specific to this aspect of e-resource management and recommends that baseline data be collected. Depending on the evidence found for high turnover, it may be more effective for libraries to address staffing issues before tackling software-implementation issues.

A final confounding influence is the prevalence of general-purpose tools whose use extends far beyond the scope of electronic-resource personnel. These are the well-known office productivity tools, a market dominated by the Microsoft Office Suite and Google's G Suite. They have become ubiquitous because they are crafted around the way most businesses work today 
(or, it might be said, because businesses have allowed themselves to be shaped by these kinds of tools). Of the 34 tools listed by responding libraries (counting responses rather than unique tools), 14 - over 40\%—were produced by Microsoft or Google. These programs accomplish a substantial portion of the work done by troubleshooting personnel. As tools supporting the specialized work of e-resources management, they are flawed but familiar. The literature might benefit from a better understanding of how widely these tools are in use at libraries (including by e-resource personnel), what activities staff in various areas use them for (including tasks they are not intended for), and whether those users are satisfied with their performance at those activities. Research might indicate that efforts could be profitably applied to customizing the functions of these common tools for nontraditional purposes or, on the contrary, that more effort should be dedicated to developing and implementing specialized tools. The present study has the potential to open a conversation about the use and relative value of general and specialized software in library technical services.

\section{Conclusion}

As mentioned in the literature review, the library literature pays considerable attention to the satisfaction of its users with technology but almost none to that of its employees. E-resources personnel are assumed to be among the most technologically savvy library workers and should be at the forefront of the technology-adoption curve. Nevertheless, technological exploration and innovation in this area have little support in the e-resources literature. There exists a major opportunity to remedy this by building on the literature of other disciplines, including consumer satisfaction, software implementation, user experience, corporate ethnography, and organizational behavior. Of course libraries and their personnel are unique, and researchers from within librarianship should be the ones to apply and expand others' work into that realm. 
The results of this study suggest several other possibilities for further research. Areas of troubleshooting activity should be categorized within a framework similar to (but narrower than) that of the TERMS project, hosted at the University of Huddersfield (Emery \& Stone, n.d.), which in turn builds on the original Electronic Resources Management Initiative (ERMI) report (Jewell et al., 2004). Empirical studies can then validate that theoretical model as a foundation for ongoing advances. A similar direction might be taken with the categorization of software tools in order to ensure the usefulness and reliability of categories studied. Further humanresources research is also needed in libraries, which could identify various factors outside of job tasks that contribute to individual employees' satisfaction with the tools for those tasks. Comparative analysis could also be valuable in this area, showing whether e-resources staff have higher or lower "burnout" rates or need unique kinds of support. These are all largely methodological concerns that would allow results to be scientifically generalizable. With a strong framework in place, the focus could turn toward collecting more substantial data sets where variables can be reliably isolated and tested. Only then can the literature of troubleshooting give robust support to practical decisions about software implementation. 


\section{References}

American Library Association. (2009). ALA's Core Competencies of Librarianship. Retrieved from

http://www.ala.org/educationcareers/sites/ala.org.educationcareers/files/content/careers/core comp/corecompetences/finalcorecompstat09.pdf

Anderson, E. K. (2014). Workflow analysis. In Electronic Resource Management Systems: A Workflow Approach: Vol. 50 No. 3. Library Technology Reports (pp. 23-30). Chicago, IL: American Library Association. https://doi.org/10.5860/1tr.50n3

Carter, S., \& Traill, S. (2017). Essential skills and knowledge for troubleshooting e-resources access issues in a web-scale discovery environment. Journal of Electronic Resources Librarianship, 29(1), 1-15. https://doi.org/10.1080/1941126X.2017.1270096

Collins, M., \& Grogg, J. E. (2011). Building a better ERMS. Library Journal, 136(4), 22-28. Retrieved from http://lj.libraryjournal.com/2011/03/digital-resources/building-a-bettererms/

Doering, W., \& Chilton, G. (2008). A locally created ERM: How and why we did it. Computers in Libraries, 28(8), 6-7, 46-48.

Ekart, D. F. (2008). Somewhere over the Verde rainbow. Computers in Libraries, 28(8), 8-10, $44-45$.

Emery, J., \& Stone, G. (n.d.). TERMS: Techniques for Electronic Resource Management. Retrieved March 20, 2017, from https://library.hud.ac.uk/blogs/terms/

Ennis, L. A., \& Tims, R. S. (2012). Help Central: Creating a help desk \& knowledge portal in SharePoint. Computers in Libraries, 32(2), 6-10.

Fox, R., \& Doshi, A. (2011). SPEC Kit 322: Library user experience. Washington, D.C.: Association of Research Libraries. 
Gustafson-Sundell, N. (2011). Think locally: A prudent approach to electronic resource management systems. Journal of Electronic Resources Librarianship, 23(2), 126-141. https://doi.org/10.1080/1941126X.2011.576955

Hartnett, E., Price, A., Smith, J., \& Barrett, M. (2010). Opening a can of wERMS: Texas A\&M University's experiences in implementing two Electronic Resource Management Systems. Journal of Electronic Resources Librarianship, 22(1/2), 18-27. https://doi.org/10.1080/1941126x.2010.486721

Heaton, R. (2018). Tools for troubleshooting: Which ones and what for. Journal of Electronic Resources Librarianship, 30(1), 1-18. doi: 10.1080/1941126X.2018.1443903

Jewell, T. D., Anderson, I., Chandler, A., Farb, S. E., Parker, K., Riggio, A., \& Robertson, N. D. M. (2004). Electronic Resource Management: Report of the DLF ERM Initiative. Retrieved from http://old.diglib.org/pubs/dlf102/

MacDonald, C. M. (2015). User experience librarians: User advocates, user researchers, usability evaluators, or all of the above? Proceedings of the Association for Information Science and Technology, 52(1), 1-10. https://doi.org/10.1002/pra2.2015.145052010055

Marquez, J. J., \& Downey, A. (2016). Library service design: a LITA guide to holistic assessment, insight, and improvement. Lantham, MD: Rowman \& Littlefield.

NASIG Core Competencies Task Force. (2016). NASIG Core Competencies for Electronic Resources Librarians. Retrieved from http://www.nasig.org/site_page.cfm?pk_association_webpage_menu=310\&pk_association_ webpage $=7802$

Rathmel, A., Mobley, L., Pennington, B., \& Chandler, A. (2015). Tools, techniques, and training: Results of an e-resources troubleshooting survey. Journal of Electronic Resources 
Librarianship, 27(2), 88-107. https://doi.org/10.1080/1941126X.2015.1029398

Samples, J., \& Healy, C. (2014). Making it look easy: Maintaining the magic of access. Serials Review, 40(2), 105-117. https://doi.org/10.1080/00987913.2014.929483

SAS Institute. (n.d.). Business Intelligence and analytics tools software revenue worldwide by vendor from 2014 to 2016 (in million U.S. dollars). Retrieved December 4, 2017, from https://www.statista.com/statistics/473009/business-intelligence-and-analytics-softwarerevenue-worldwide-by-vendor/

Welzenbach, R. (2014). Introducing Weave: Journal of Library User Experience. Retrieved December 4, 2017, from https://www.publishing.umich.edu/2014/10/09/introducing-weavejournal-library-user-experience/

Wilson, K. (2011). Beyond library software: New tools for electronic resources management. Serials Review, 37(4), 294-304. https://doi.org/10.1016/j.serrev.2011.09.010 